\title{
Pre-harvest Sprouting and Grain Dormancy in Sorghum bicolor: What Have We Learned?
}

OPEN ACCESS

Edited by:

Hiroyuki Nonogaki,

Oregon State University,

United States

Reviewed by:

Shingo Nakamura,

Institute of Crop Science (NARO),

Japan

Jirui Wang

Sichuan Agricultural University, China

*Correspondence:

Roberto L. Benech-Arnold

benech@agro.uba.ar

Specialty section:

This article was submitted to

Plant Breeding,

a section of the journal

Frontiers in Plant Science

Received: 18 April 2018

Accepted: 25 May 2018

Published: 15 June 2018

Citation:

Benech-Arnold RL and Rodríguez MV

(2018) Pre-harvest Sprouting and Grain Dormancy in Sorghum bicolor: What Have We Learned?

Front. Plant Sci. 9:811.

doi: $10.3389 /$ fpls.2018.00811

\begin{abstract}
Roberto L. Benech-Arnold ${ }^{1,2 *}$ and Maria V. Rodríguez ${ }^{2,3}$
${ }^{1}$ Cátedra de Cultivos Industriales, Departamento de Producción Vegetal, Facultad de Agronomía, Universidad de Buenos Aires, Buenos Aires, Argentina, ${ }^{2}$ Instituto de Fisiología y Ecología Vinculado a la Agricultura, Consejo Nacional de Investigaciones Cientificas y Técnicas, Facultad de Agronomía, Universidad de Buenos Aires, Buenos Aires, Argentina, ${ }^{3}$ Cátedra de Fisiología Vegetal, Departamento de Biología Aplicada y Alimentos, Facultad de Agronomía, Universidad de Buenos Aires, Buenos Aires, Argentina
\end{abstract}

The possibility of obtaining sorghum grains with quality to match the standards for a diversity of end-uses is frequently hampered by the susceptibility to pre-harvest sprouting (PHS) displayed by many elite genotypes. For these reasons, obtaining resistance to PHS is considered in sorghum breeding programs, particularly when the crop is expected to approach harvest maturity under rainy or damp conditions prevalence. As in other cereals, the primary cause for sprouting susceptibility is a low dormancy prior to crop harvest; in consequence, most research has focused in understanding the mechanisms through which the duration of dormancy is differentially controlled in genotypes with contrasting sprouting behavior. With this aim two tanninless, red-grained inbred lines were used as a model system: IS9530 (sprouting resistant) and Redland B2 (sprouting susceptible). Redland B2 grains are able to germinate well before reaching physiological maturity (PM) while IS9530 ones can start to germinate at 40-45 days after pollination, well after PM. Results show that the anticipated dormancy loss displayed by Redland B2 grains is related reduced embryo sensitivity to abscisic acid (ABA) and increased levels of GA upon imbibition. In turn, transcriptional data showed that ABA signal transduction is impaired in Redland B2, which appears to have an impact on GA catabolism, thus affecting the overall GA/ABA balance that regulates germination. QTL analyses were conducted to test whether previous candidate genes were located in a dormancy QTL, but also to identify new genes involved in dormancy. These analyses yielded several dormancy QTL and one of them located in chromosome 9 (qGl-9) was consistently detected even across environments. Fine mapping is already in progress to narrow down the number of candidate genes in qGl-9.

Keywords: Sorghum bicolor, grain sorghum, pre-harvest sprouting, seed dormancy, abscisic acid, dormancy QTL

\section{INTRODUCTION}

Grain sorghum [Sorghum bicolor (L.) Moench] is a grass species cultivated for its grain which is used for feeding both humans and animals. Also known as durra, jowari, or milo, sorghum can grow under harsher conditions and therefore may be better than maize or sugarcane in some environments. Sorghum originated in Northern Africa but is now cultivated widely in tropical 
and subtropical environments to the point that it has become the fifth most important cereal of the world after rice, wheat, maize, and barley. Sorghum grains for human consumption are used to make flat breads and beverages and also for malting and brewery. As in many other crops, the sorghum grain is also required to perform as the propagule for a new crop. The possibility of obtaining grains with quality to match the standards for these end-uses is frequently hampered by the susceptibility to pre-harvest sprouting (PHS) displayed by many elite genotypes. Indeed, untimely germination in the mother plant promotes reserve mobilization and/or leads to either immediate loss of seed viability or to a large reduction in seed longevity (Del Fueyo et al., 2003). In addition, sorghum sprouts accumulate toxic amounts of cyanide (Ikediobi et al., 1988). For these reasons, obtaining resistance to PHS is one of the main objectives in sorghum breeding programs, particularly when the crop is expected to approach harvest maturity under rainy or damp conditions prevalence. As in other cereals, the primary cause for sprouting susceptibility is a low dormancy prior to crop harvest (see Rodríguez et al., 2015). Consequently, efforts have been directed to understand the mechanisms through which the duration of dormancy is differentially controlled in genotypes with contrasting sprouting behavior. In this review paper, we discuss the current understanding of the mechanisms that impose dormancy to the sorghum grain, and mention on-going work directed toward breeding for PHS tolerance.

\section{WHERE IS DORMANCY LOCATED IN THE SORGHUM GRAIN?}

The sorghum grain is a caryopsis (Waniska and Rooney, 2002). Depending on the genotype, this caryopsis may be "naked" or covered to different extents by the hulls (consisting of the glumellae - lemma and palea - and the glumes). The grain comprises an embryo, reserve tissue (corneous and starchy endosperm, surrounded by the aleurone layer), and the seed coat (nucellus and testa) fused to the pericarp. As in other cereals, the external structures of the sorghum grain, including testa, pericarp, and hulls, can impose dormancy to the underlying embryo. These structures may accumulate various phenolic compounds, such as phenolic acids, coumarins, flavonoids, and tannins (Glennie, 1981; Dykes et al., 2009). Increased pigmentation has been frequently associated with deeper dormancy in cereals like rice, wheat, barley, and maize (as discussed in Rodríguez et al., 2015). Flavonoid compounds may have an inhibitory effect per se, as chemically active inhibitors of germination, or through an effect on permeability to gas exchange in the imbibed seed (as discussed in Rodríguez et al., 2015). Nevertheless, genetic studies have usually found that pigmentation-related loci that co-locate with loci for PHS or germination traits correspond with transcriptional regulators rather than structural genes involved in pigment biosynthesis. Red colored grains accumulate phlobaphenes or anthocyanins in the pericarp. Regulation of phlobaphene synthesis is exerted by R2R3-MYB transcriptional factors, as encoded by the P1 gene in maize and Yellow seed1 in sorghum (Kambal and Bate-Smith, 1976; Boddu et al., 2005; Ibraheem et al., 2015), whereas regulation of anthocyanin synthesis is controlled by transcriptional complexes consisting of R2R3-MYB, basic-helixloop-helix (bHLH), and WD-repeat (WDR) proteins (MBW complex; Liu et al., 2015). Mutations in some of these genes can affect dormancy through pleiotropic effects on different pathways. In weedy red rice, SD7-1 (a BHLH-type regulator) activates simultaneously flavonoid and abscisic acid (ABA) synthesis genes in the developing seed, conferring red color and deep dormancy (Gu et al., 2011). Maize VIVIPAROUS-1 (VP1) is required for ABA signal transduction in the developing grain, and also regulates the expression of $C 1$ (encoding an R2R3 MYB factor) that promotes anthocyanin synthesis in the aleurone (McCarty et al., 1989). Loss-of-function alleles of Tamyb10 (red pericarp, R-1 loci) in wheat and Hvmyb10 in barley fail to accumulate proanthocyanidins in the testa and contribute to reduce grain sensitivity to $\mathrm{ABA}$ and dormancy (Himi et al., 2002; Himi and Noda, 2005). Sorghum grains can accumulate variable levels of flavonoids, including phlobaphenes in the outer pericarp and proanthocyanidines (condensed tannins) in the underlying testa (Cheng et al., 2009). Accumulation of tannins in the testa is independent of pericarp color and is controlled by Tannin1, a WD40-type transcriptional regulator (Wu et al., 2012). In a study with 42 sorghum hybrids by Harris and Burns (1970), a negative correlation between germination index and astringent tannin content was observed. Also, among tanninless sorghums, red grained varieties are usually more resistant to PHS than genotypes with yellow and white grains, although no strict correlation has been demonstrated so far. A direct role for Tannin1 and Yellow seed 1 in dormancy remains to be tested. Because condensed tannins are considered to reduce the nutritional value of the sorghum grain, research on PHS tolerance has focused on tannin-less sorghum varieties.

As reported for other cereals, the inability of the sorghum grains to germinate at harvest or before [i.e., from 20 days after pollination (DAP) onward] is due to a complex interplay between coat- and embryo-based dormancy, with the former playing a major role in the overall contribution to grain dormancy. Removal of the covering structures (i.e., pericarp, testa and endosperm) results in a reduced expression of dormancy at a wide range of temperatures even with embryos isolated as early as 15 DAP (Benech-Arnold et al., 1991; Steinbach et al., 1995). However, different responsiveness to inhibitory factors such as $\mathrm{ABA}$, as well as different accumulation of promoting factors such as gibberellins (GAs), support that embryo-related factors are relevant in the expression of different levels of coat-imposed dormancy.

\section{THE SYSTEM REDLAND B2 - IS9530}

During the last 25 years, studies on the physiological and genetic bases of PHS resistance in sorghum were conducted using two inbred, red-grained lines as a model system: IS9530, a tall, tannin-less line derived from ICRISAT breeding program, and Redland B2 (originally registered as Redlan, or BTx378), an also tannin-less, three-dwarf derivative line, resulting from the 
US Sorghum Conversion Program (Stephens et al., 1967). During this program, sorghums were substituted with several height and maturity genes to obtain short, early forms in temperate zones. Despite their different background, both IS9530 and RedlandB2 display similar phenology at our latitude under sowing dates taking place between the last week of November and the first week of December. The sprouting behavior of these two inbred lines, however, is contrasting: the Redland B2 line is susceptible to PHS, while the IS9530 one is resistant. The nature of this contrasting behavior relies on the anticipated exit from dormancy of the Redland B2 grains which are able to germinate well before reaching physiological maturity (PM); IS9530 grains, in contrast, can start to germinate at 40-45 DAP, well after PM (Figure 1; Steinbach et al., 1995, 1997). Isolated embryos from both lines can germinate very quickly even before 20 DAP (Figure 1) demonstrating that the different capacity to germinate during development is the result of dormancy differentially imposed by the presence of the seed coat tissues. The pattern of dormancy release during grain filling normally shows two phases in Redland B2 grains: an early one which is not observed in IS9530 grains, starting around 15-20 DAP and reaching a plateau prior to PM (30-35 DAP), and a second one starting after PM and coinciding with the beginning of exit from dormancy in IS9530 grains (Figure 1). Susceptibility to PHS in Redland B2, then, is related to precocious grain dormancy loss, while resistance in IS9530 can be associated to a more persistent dormancy (Steinbach et al., 1995). It is well known, as in many other species, that the expression of dormancy in sorghum depends on the incubation temperature: dormancy is very much expressed at low incubation temperatures (i.e., $15-20^{\circ} \mathrm{C}$ ), while it is barely expressed at high temperatures (i.e., $30-35^{\circ} \mathrm{C}$; Benech-Arnold et al., 2003). For these reasons, differences in the sprouting behavior between these two lines are exacerbated when damp conditions prior to harvest are combined with mild ambient temperatures $\left(20^{\circ} \mathrm{C}\right.$ or below $)$ that favor the expression of dormancy.

\section{HORMONAL REGULATION OF DORMANCY IN THE DEVELOPING SORGHUM GRAIN}

A crucial role for $\mathrm{ABA}$ in the imposition of physiological dormancy in the developing seed has been demonstrated in many species (Finkelstein et al., 2002). Mutant seeds of Arabidopsis and maize that are ABA-deficient or ABA-insensitive germinate precociously (Robichaud et al., 1980; Karssen et al., 1983). No sorghum mutants for ABA synthesis or metabolism have been reported, but application of the ABA-synthesis inhibitor fluridone during early seed development accelerated dormancy release in dormant IS9530 sorghum line (Steinbach et al., 1997), as expected from earlier experiments with fluridone that produced vivipary in maize (Fong et al., 1983). However, embryos from the more dormant line IS9530 were found to have a similar ABA content throughout development to embryos from the less dormant line Redland B2 (Steinbach et al., 1995). Embryonic content of ABA decreased gradually during phase two of imbibition, but this decrease was similar for both lines and

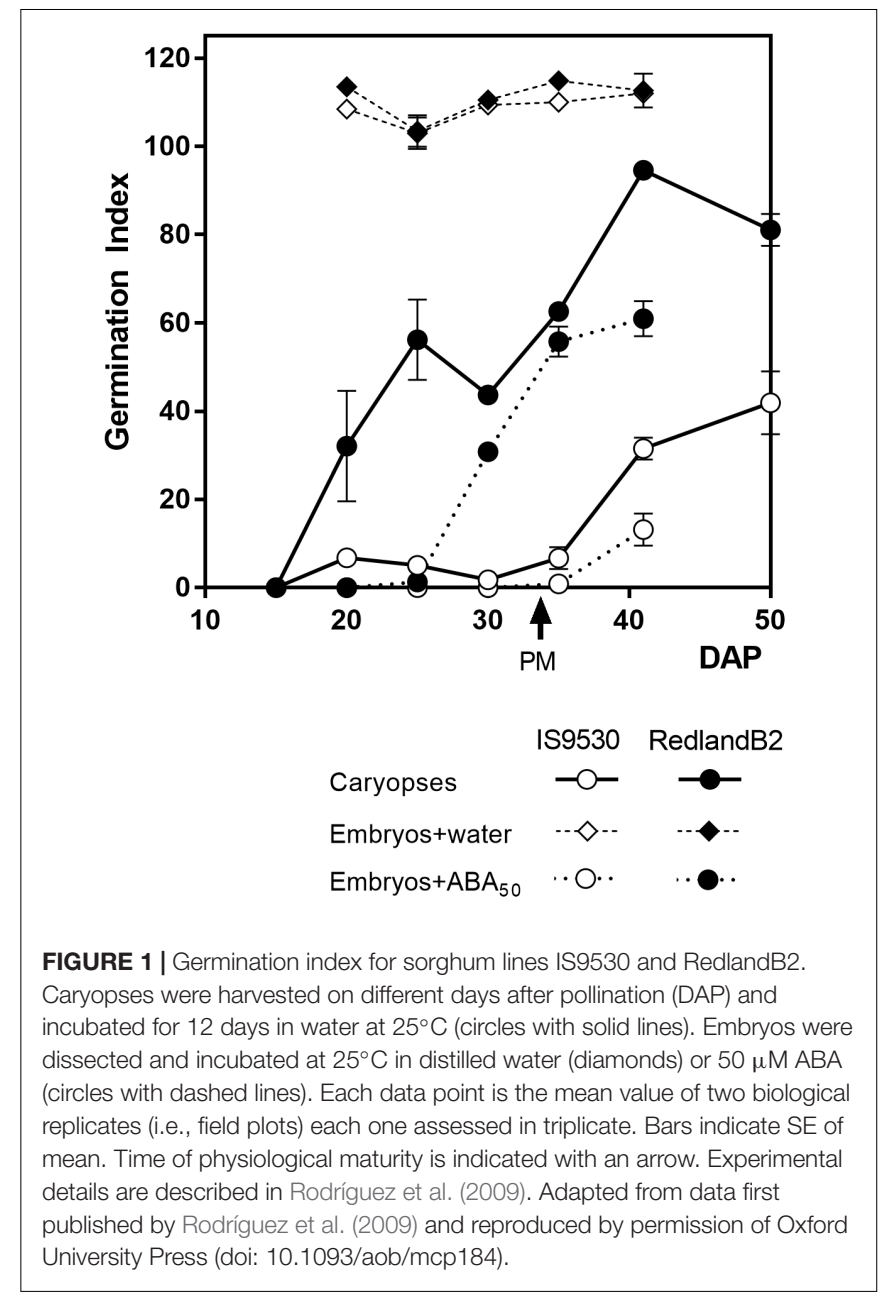

did not relate with their germination response (Rodríguez et al., 2009). The seed coats were found to delay ABA leakage from the embryo to the medium, as ABA content decreased rapidly when isolated embryos were incubated in water (Gualano et al., 2007). This is due to the fact that ABA easily leaks from the naked embryo into the incubation medium, and suggests that the covers impose dormancy to the embryo, at least in part, by reducing ABA leakage. Instead, suppression of germination of Redland B2 embryos required ABA concentrations 10-fold higher than those required for inhibiting germination of IS 9530 embryos; moreover, this difference was maintained throughout the whole developmental period and even beyond PM (Figure 1; Steinbach et al., 1995). These results confirmed that the observed differences in responsiveness to $\mathrm{ABA}$ are due to functional differences in the ABA signaling pathway and not in embryonic ABA concentration (Gualano et al., 2007).

It has been known for a long time that GAs promote germination of dormant seeds in many species, antagonizing the inhibitory effect of ABA. Both ABA and GA also act antagonistically in the inception of dormancy during early development. Application of paclobutrazol, a GA biosynthesis inhibitor to young sorghum panicles, reduced GA content during development and delayed dormancy release for several weeks 
in Redland B2 grains (Steinbach et al., 1997). Moreover, the incubation of immature IS9530 grains coming from fluridonetreated panicles, in the presence of $\mathrm{GA}_{4}+7$, resulted in a pattern of exit from dormancy throughout development that resembled that of Redland B2 grains (Steinbach et al., 1997). Indeed, the first phase of dormancy release displayed by Redland B2 grains but not by IS 9530 ones (Figure 1), was mimicked by combining low ABA content with exogenous GA supplementation. These results suggested that the anticipated dormancy release displayed by Redland B2 grains was not only related to a low embryo responsiveness to $\mathrm{ABA}$, but also to a high GA content or, alternatively, to a high capacity to synthesize GA de novo upon imbibition. Similar to observations of ABA content in developing grains of these two genotypes, no correlation was found between natural endogenous GA content and dormancy (Benech-Arnold et al., 2000). Instead, analysis of GA content in these same sorghum lines revealed that, in Redland B2, but not in IS 9530, $\mathrm{GA}_{4}$ content increased during imbibition and before completion of germination (Pérez-Flores et al., 2003). This increase in $\mathrm{GA}_{4}$ was directly related to a reduction in catabolite $\mathrm{GA}_{34}$ (Rodríguez et al., 2012) suggesting that GA catabolism has an active role in regulating $\mathrm{GA}_{4}$ levels. Taken together, these results suggest that the anticipated dormancy loss displayed by Redland B2 grains is related to a reduced embryo sensitivity to ABA and increased levels of GA upon imbibition. Therefore, both GA metabolism (in particular, GA catabolism) and ABA signaling appeared as the main components of the ABA/GA balance regulating the germination response in developing grains of both lines. A candidate gene approach was followed to assess and identify potential regulatory sites at the transcriptional level that would lead to the observed differences at the physiological level.

\section{EXPRESSION OF SEVERAL ABA SIGNALING GENES AND A GA CATABOLISM GENE IS UPREGULATED IN IMBIBED, DORMANT IS9530 GRAINS BEFORE - BUT NOT AFTER - PM}

Expression analyses were conducted for several candidate genes involved in ABA signaling and GA metabolism (Rodríguez et al., 2009, 2012). Orthologous sequences for the candidate genes in sorghum were obtained by searching the sorghum genome published by Paterson et al. (2009). Consistently with differences in sensitivity to $\mathrm{ABA}$, a transient and coordinated up-regulation of $S b A B I 3 / V P 1, S b A B I 4, S b A B I 5$, and $S b P K A B A 1$ (together with SbABI5 protein levels) occurred in imbibed grains of IS9530, but not in RedlandB2. This "induction" pattern in IS9530 was observed in immature grains (30 DAP), but after PM expression of these genes decreased rapidly and similarly in both lines (Rodríguez et al., 2009). This synchronous expression of main ABA signaling genes is in agreement with published results in Arabidopsis, where extensive cross-regulation has been demonstrated among VP1/ABI3, ABI4, and ABI5 (Lopez-Molina et al., 2002; Reeves et al., 2011).
Transcriptional analysis of several sorghum genes encoding putative GA synthesis enzymes ( $S b E K O, S b E K A H, S b G A 20 o x 2$, $S b G A 200 \times 3$, and SbGA3ox1) showed, on the other hand, a transient increase in dormant grains (IS9530) during the first 2-3 days of grain imbibition, which did not occur in Redland B2 (Rodríguez et al., 2012). This evidence appears to be in contradiction with changes in $\mathrm{GA}_{4}$ levels in both lines. However, simultaneously with this enhanced expression of GA synthesis genes in dormant IS9530 grains, expression of GA inactivation genes $S b G A$ 2-oxidase1 and Sb GA 2-oxidase3 (SbGA2ox1 and $S b G A 2 o \times 3)$ was also increased This observation, together with a negative association between embryo content of active $\mathrm{GA}_{4}$ and its corresponding catabolite $\mathrm{GA}_{34}$, supported the notion that $\mathrm{GA}_{4}$ levels remain low in dormant IS9530 grains as a result of a prominent catabolic activity by GA2-oxidases, which, in turn, is reduced in RedlandB2. On the other hand, incubation of dormant grains in $100 \mu \mathrm{M} \mathrm{GA}$ promoted germination but did not reduce the expression of most key GA synthesis genes, ruling out the idea of a negative feedback regulatory mechanism driven by active GAs. In addition, and in contrast to other reports which show a feed-forward mechanism affecting expression of GA2-oxidase genes by active GA levels in Arabidopsis (Ogawa et al., 2003; Rieu et al., 2008), expression of sorghum SbGA2-ox1 and $S b G A 2-o x 3$ was downregulated by exogenously applied $\mathrm{GA}_{3}$ (Rodríguez et al., 2012). The similar expression profiles obtained for $S b A B I 4, S b A B I 5$ (together with SbABI5 protein abundance), and $S b G A 2$-oxidase genes suggested the existence of a possible functional link between both pathways. This, together with the presence of an ABA-responsive complex (ABRC) conformed by cis-regulatory elements related to ABA (ABRE, RY repeat, and $\mathrm{CE}$ ) in the $5^{\prime}$ regulatory region of $G A-20 \times 3$, suggested a possible interaction between ABA signaling pathway and GA catabolism (Rodríguez et al., 2009, 2012). This interaction was tested by Cantoro et al. (2013). In this work, SbABI4 and SbABI5 proteins were shown to interact in vitro with a fragment of the SbGA2-ox3 promoter containing the above-mentioned ABRC. Both transcription factors were able to bind the promoter, although not simultaneously, suggesting that they might compete for the same cis-acting regulatory sequences. A biological role for these interactions in the expression of dormancy of sorghum grains was proposed: either SbABI4 and/or SbABI5 activate transcription of the $S b G A 2$-oxidase 3 gene in vivo and promote SbGA2-oxidase3 protein accumulation; this would result in active degradation of $\mathrm{GA}_{4}$, thus preventing germination of dormant grains. A comparative analysis of the $5^{\prime}$-regulatory region of GA2-oxidase genes from both monocots and dicots showed that GA2-oxidase genes with an ABRC in their promoter region are exclusive to a conserved sub-group found in monocots (subgroup M3, according to Cantoro et al., 2016) to which SbGA2-ox3 belongs. Conservation of the ABRC in closely related GA2oxidases from Brachypodium distachyon and rice suggests that these species might share the same regulatory mechanism as proposed for grain sorghum.

In summary, physiological evidence (showing similar endogenous ABA levels but contrasting response to exogenous ABA) and transcriptional data (showing different expression levels of ABA signaling genes but also of ABI5 protein levels) 
support that ABA signal transduction is impaired in Redland B2. Reduced ABA signaling appears to have an impact on GA catabolism, thus affecting the overall GA/ABA balance that regulates germination.

\section{GENETIC APPROACH: MAPPING OF "OLD" CANDIDATE AND "NEW" DORMANCY GENES}

Quantitative trait loci (QTL) analyses were conducted to investigate the genetic bases of the contrasting dormancy phenotypes in both sorghum inbred lines IS 9530 and Redland B2. This approach would allow testing whether previous candidate genes are located in a dormancy QTL, but also would lead to the identification of new genes involved in dormancy. The first genetic study was done by Lijavetzky et al. (2000) with an $F_{2}$ mapping population derived from a cross between IS9530 x Redland B2. These authors used
RFLP, RAPDs, and AFLP markers, and reported a putative association between SbVP1 and a dormancy QTL in likage group "E” (Carrari et al., 2003). To further confirm and expand these results, a new mapping population was obtained from the same sorghum parents, the genetic map was constructed using SSR markers, and phenotypic data were obtained at 34 (before PM) and 45 (after PM) DAP (Cantoro et al., 2016). In this work, six QTLs were identified for seed dormancy (Figure 2) in 42 DAP grains (qGI-1, qGI-3, qGI-4, qGI6, qGI-7, and qGI-9) which were successfully anchored on the S. bicolor genome assembly v2.1 (Paterson et al., 2009) through QTL flanking SSR physical position. The number of genes within these intervals ranged from 75 ( $q$ GI-9) to 547 ( $q G I-3)$. No epistasis was detected for the identified QTL. Interestingly, $S b A B I 3 / V P 1$ located within qGI-3, which makes it a good candidate to be the causal gene for this QTL. Allelic variants for SbVP1 were found to exist in RedlandB2 and IS9530 (Carrari et al., 2001). The sorghum VP1 gene encodes a 699 amino acid predicted protein, and sequences

\section{Linkage Map $\mathrm{F}_{2: 3}$ Population (IS9530 x Redland B2)}
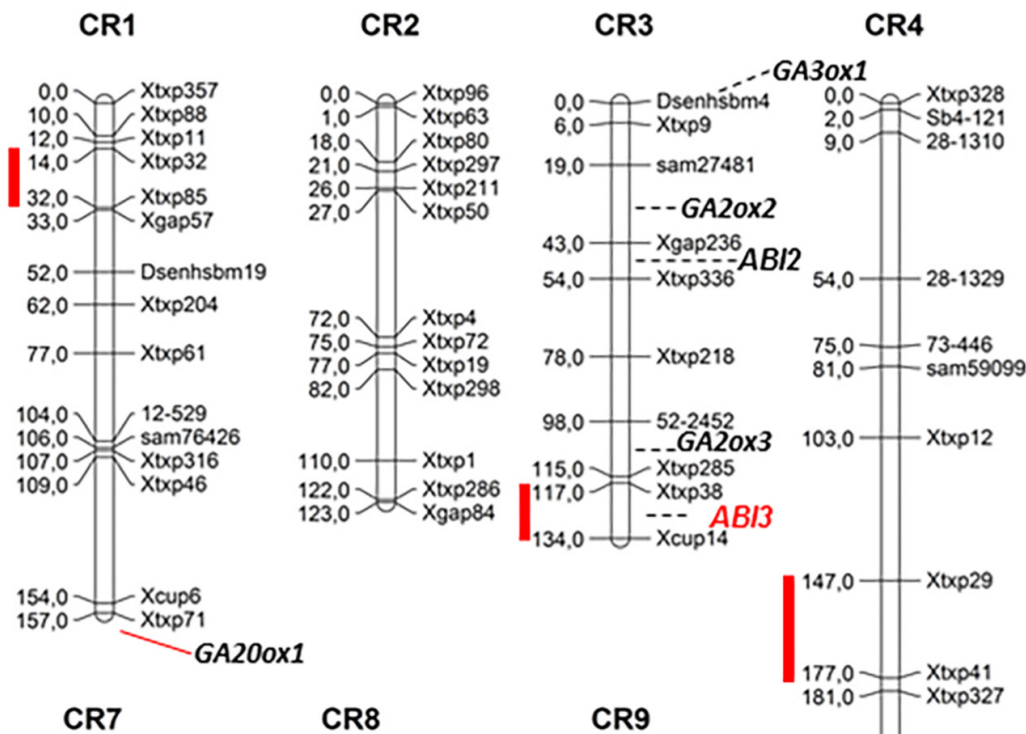

\section{CR6}
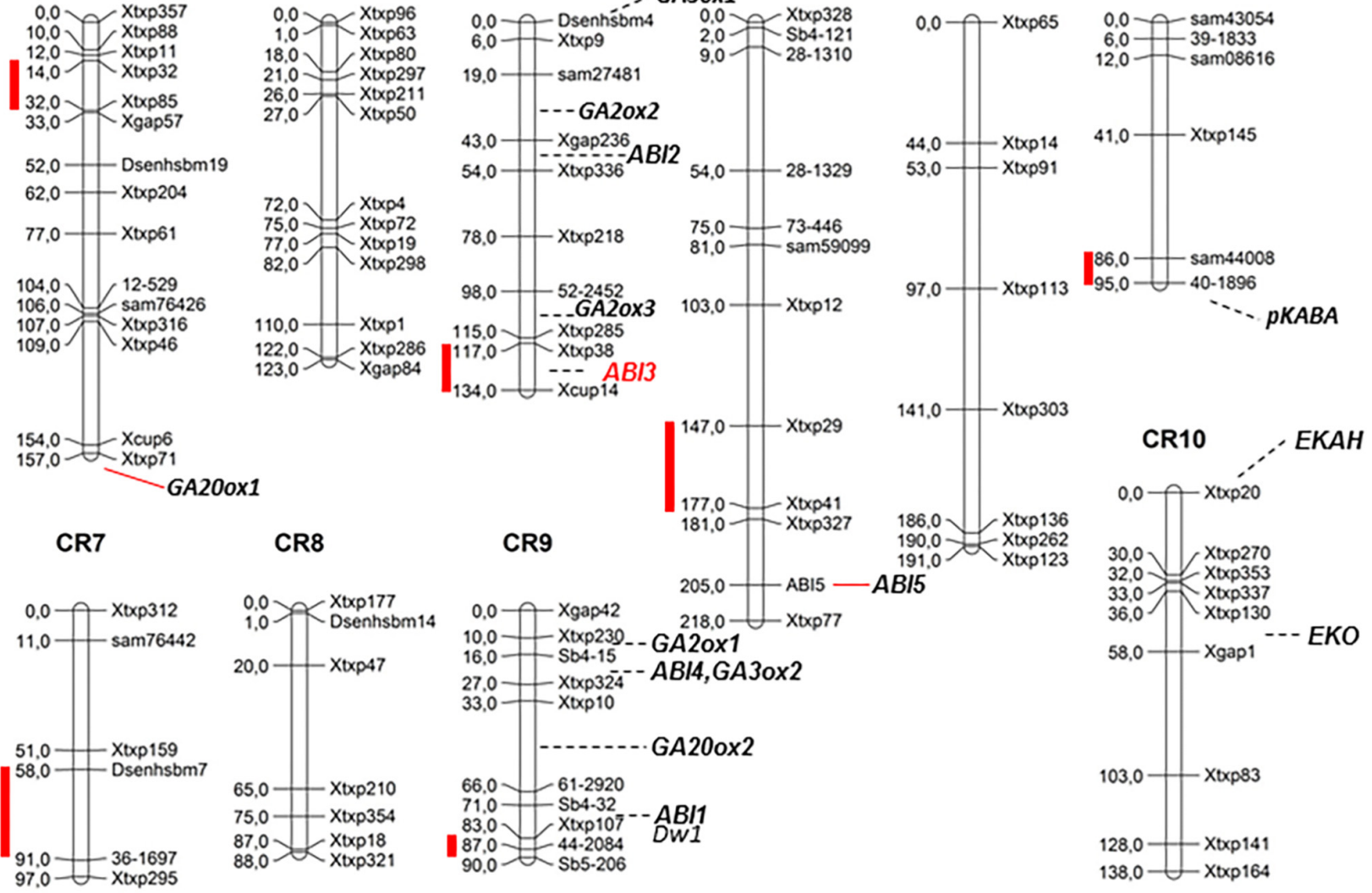

FIGURE 2 | Genetic linkage map for F2 grain sorghum population, derived from IS9530 and RedlandB2 inbred lines, built with 96 SSRs segregation analysis

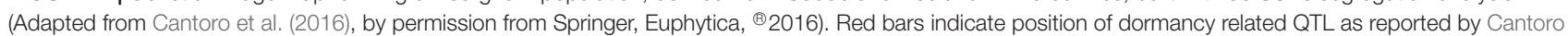
et al. (2016). Marker names are shown on the right side of each chromosome and genetic distances between markers (in cM) are indicated on the left side. Positions of Dwarf1, and ABA signaling and GA metabolism candidate genes are shown. 
obtained for RedlandB2 and IS9530 differ in two residues at positions 341 (Gly/Cys, within the repression domain) and 448 (Pro/Ser; Carrari et al., 2001). These replacements might result in different biological functions, particularly the one located in the repression domain (Hoecker et al., 1995). Interestingly, in Arabidopsis seeds of abi3 mutants, ABI5 expression was greatly reduced (Lopez-Molina et al., 2002), while ectopic expression of maize VP1 in Arabidopsis abi3 background inhibited $A B I 1 / A B I 2$ induction by ABA (Suzuki et al., 2003). An altered functionality of Redland B2 SbVP1 allele appears as a possible cause for the altered expression of other ABA signaling genes as observed in imbibed, developing grains. Future experiments will test whether sorghum allelic variants for SbVP1 have different activation/repression activity, together with fine mapping for this QTL. In parallel, synteny analysis of all detected QTL was also carried out and, besides VP1, no previous dormancyrelated loci reported in other cereals were found to locate with sorghum QTLs reported by our group (Cantoro et al., 2016).

Ongoing work relies on a recombinant inbred line (RIL) population derived from the $\mathrm{F}_{3}$ mapping population used by Cantoro et al. (2016). This population was phenotyped recently for several dormancy-related traits, including sprouting in the field which occurred naturally in 2016. A new set of SNP markers was used, and due to an unbalanced coverage in several chromosome regions, QTL detection was limited to chromosome 9. Using two-year phenotypic data obtained before and after PM, qGI-9 (as reported by Cantoro et al., 2016) was identified again in this new RIL population. Improved marker coverage is expected to allow detection of previous dormancy QTLs including qGI-3. Interestingly, the region containing the dormancy locus in qGI-9 is very close to $D W A R F-1$, a gene regulating plant stature and recently cloned by two groups (Hilley et al., 2016; Yamaguchi et al., 2016). Sorghum DW1 protein positively regulates brassinosteroid (BR) signaling and plant stature by inhibiting a negative regulator of BR signaling, BIN2 (Hirano et al., 2017). The genomic region in chromosome 9 carrying the loss-of-function dw1 allele has been introduced into many elite lines during the Sorghum Conversion Program to reduce plant stature, including RedlandB2 and BTx623. As the Standard

\section{REFERENCES}

Benech-Arnold, R. L., Enciso, S., Sánchez, R. A., Carrari, F., Pérez-Flores, L., Iusem, N., et al. (2000). "Involvement of ABA and GAs in the regulation of dormancy in developing sorghum seeds," in Seed Biology: Advances and Applications, eds M. Black, K. J. Bradford, and J. V. ázquez-Ramos (Wallingford: CABI Publishing), 101-111. doi: 10.1079/9780851994048.0101

Benech-Arnold, R. L., Fenner, M., and Edwards, P. J. (1991). Changes in germinability, ABA levels and ABA embryonic sensitivity in developing seeds of Sorghum bicolor induced by water stress under grain filling. New Phytol. 118, 339-347. doi: 10.1111/j.1469-8137.1991.tb00986.x

Benech-Arnold, R. L., Rodriguez, M. V., Sánchez, R. A., Carrari, F., Pérez-Flores, L. J., Osuna-Fernández, H. R., et al. (2003). "Physiological and molecular aspects of the control of dormancy and germination in developing sorghum caryopses," in The Biology of Seeds: Recent Research Advances, eds G. Nicolás, K. J. Bradford, D. Come, and H. W. Pritchard (Oxon: CAB International), 11-23.

Boddu, J., Svabek, C., Ibraheem, F., Jones, A. D., and Chopra, S. (2005). Characterization of a deletion allele of a sorghum Myb gene, yellow seed 1
Yellow Milo background (where the $d w 1$ mutation originated; Quinby and Karper, 1961) displays very low dormancy prior to harvest, it is likely that a low-dormancy allele was introduced together with the $d w 1$ allele during breeding for reduced height. Low heterozygocity along this region of chromosome 9 in a large GWAS panel (Morris et al., 2013) suggests that, if both $d w 1$ and the qGI-9 causal gene are linked, then many elite parental lines harbor this low dormancy allele. Current work involves the obtention of NILs for fine mapping of both qGI-3 and qGI-9 and genotyping by sequencing (GBS) of parental lines. Both strategies are aimed to narrow down the number of candidate genes in these regions and identify DNA polymorphisms in these genes. Future studies including transcriptomic analysis of developing grains for both parental lines are expected to help identify potential transcriptional variants (due to polymorphisms in the promoter region) among the candidate genes within each QTL. Strategies based on the combination of genetic and genomic tools have accelerated the process leading to identify a solid, causal gene for a QTL. An example of this is the identification of MOTHER OF FT (MFT) as the causal gene of a dormancy QTL (QPhs.ocs-3A.1) in wheat by Nakamura et al. (2011). Confirmation of the role of the proposed candidate genes for qGI-9 and qGI-3 in the dormancy phenotype will require functional testing either in sorghum or in other model organisms.

\section{AUTHOR CONTRIBUTIONS}

All authors listed above made a substantial, direct and intellectual contribution to this work. RB-A and MR discussed the contents and wrote the first version of the manuscript. MR corrected the revised version. Both authors read and approved the final version for publication.

\section{FUNDING}

This work was financed with grant no. PICT 20131357 from the Agencia Nacional de Promoción Científica y Tecnológica, Argentina.

showing loss of 3-deoxyflavonoids. Plant Sci. 169, 542-552. doi: 10.1016/j. plantsci.2005.05.007

Cantoro, R., Crocco, C. D., Benech-Arnold, R. L., and Rodríguez, M. V. (2013). In vitro binding of Sorghum bicolor transcription factors ABI4 and ABI5 to a conserved region of a GA 2-OXIDASE promoter: possible role of this interaction in the expression of seed dormancy. J. Exp. Bot. 64, 5721-5735. doi: $10.1093 /$ jxb/ert347

Cantoro, R., Fernández, L. G., Cervigni, G. D. L., Rodríguez, M. V., Gieco, J. O., Paniego, N., et al. (2016). Seed dormancy QTL identification across a Sorghum bicolor segregating population. Euphytica 211, 41-56. doi: 10.1007/s10681-0161717-z

Carrari, D., Benech-Arnold, R. L., Osuna-Fernández, R., Hopp, E., Sánchez, R., Iusem, N., et al. (2003). Genetic mapping of the Sorghum bicolor VP1 gene and its relationship with pre-harvest sprouting resistance. Genome 46, 253-258. doi: $10.1139 / g 02-129$

Carrari, F., Perez-Flores, L. J., Lijavetzky, D., Enciso, S., Sánchez, R. A., BenechArnold, R. L., et al. (2001). Cloning and expression of a sorghum gene with homology to maize VP1. Its potential involvement in pre-harvest 
sprouting resistance. Plant Mol. Biol. 45, 631-640. doi: 10.1023/A:10106484 20669

Cheng, S., Sun, Y., and Halgreen, L. (2009). The relationships of sorghum kernel pericarp and testa characteristics with tannin content. Asian J. Crop Sci. 1, 1-5.

Del Fueyo, P. A., Sánchez, R. A., and Benech-Arnold, R. L. (2003). Seed longevity in two sorghum varieties with contrasting dormancy level prior to harvest. Seed Sci. Technol. 31, 639-650. doi: 10.15258/sst.2003.31.3.13

Dykes, L., Seitz, L. M., Rooney, W. L., and Rooney, L. W. (2009). Flavonoid composition of red sorghum genotypes. Food Chem. 116, 313-317. doi: 10.1016/ j.foodchem.2011.03.020

Finkelstein, R. R., Gampala, S. S. L., and Rock, C. D. (2002). Abscisic acid signaling in seeds and seedlings. Plant Cell 14(Suppl. 1), S15-S45. doi: 10.1105/tpc.010441

Fong, F., Smith, J. D., and Koehler, D. E. (1983). Early events in maize seed development. Plant Physiol. 73, 899-901. doi: 10.1104/pp.73.4.899

Glennie, C. W. (1981). Preharvest changes in polyphenols, peroxidase, and polyphenol oxidase in Sorghum grain. J. Agric. Food Chem. 29, 33-36. doi: 10.1021/jf00103a009

Gu, X. Y., Foley, M. E., Horvath, D. P., Anderson, J. V., Feng, J., Zhang, L., et al. (2011). Association between seed dormancy and pericarp color is controlled by a pleiotropic gene that regulates abscisic acid and flavonoid synthesis in weedy red rice. Genetics 189, 1515-1524. doi: 10.1534/genetics.111.131169

Gualano, N., Carrari, F., Rodríguez, M. V., Pérez-Flores, L., Sánchez, R. A., Iusem, N. D., et al. (2007). Reduced embryo sensitivity to ABA in sprouting susceptible sorghum (Sorghum bicolor) variety is associated with an altered ABA signalling. Seed Sci. Res. 17, 81-90. doi: 10.1017/S0960258507708115

Harris, H. B., and Burns, R. E. (1970). Influence of tannin content on preharvest seed germination in sorghum. Agronomy J. 62, 835-836. doi: 10.2134/ agronj1970.00021962006200060051x

Hilley, J., Truong, S., Olson, S., Morishige, D., and Mullet, J. (2016). Identification of Dw1, a regulator of sorghum stem internode length. PLoS One 11:e0151271. doi: 10.1371/journal.pone.0151271

Himi, E., Mares, D. J., Yanagisawa, A., and Noda, K. (2002). Effect of grain color gene (R) on grain dormancy and sensitivity of the embryo to abscisic acid (ABA) in wheat. J. Exp. Bot. 3, 1569-1574. doi: 10.1093/jxb/erf005

Himi, E., and Noda, K. (2005). Red grain color gene (R) of wheat is a Myb-type transcription factor. Euphytica 143, 239-242. doi: 10.1007/s10681-005-7854-4

Hirano, K., Kawamura, M., Araki-Nakamura, S., Fujimoto, H., OhmaeShinohara, K., Yamaguchi, M., et al. (2017). Sorghum DW1 positively regulates brassinosteroid signaling by inhibiting the nuclear localization of BRASSINOSTEROID INSENSITIVE 2. Sci. Rep. 7, 126. doi: 10.1038/s41598017-00096-w

Hoecker, U., Vasil, I. K., and McCarty, D. R. (1995). Integrated control of seed maturation and germination programs by activator and repressor functions of Viviparous-1 of maize. Genes Develop. 9, 2459-2469. doi: 10.1101/gad.9.20. 2459

Ibraheem, F., Gaffoor, I., Tan, Q., Shyu, C., and Chopra, S. (2015). A sorghum MYB transcription factor induces 3-Deoxyanthocyanidins and enhances resistance against leaf blights in maize. Molecules 20, 2388-2404. doi: 10.3390/ molecules 20022388

Ikediobi, C. O., Olugboji, O., and Okoh, P. N. (1988). Cyanide profile of component parts of sorghum (Sorghum bicolor L. Moench) sprouts. Food Chem. 27, 167-175. doi: 10.1016/0308-8146(88)90059-3

Kambal, A. E., and Bate-Smith, E. C. (1976). A genetic and biochemical study on pericarp pigments in a cross between two cultivars of grain sorghum, Sorghum bicolor. Heredity 37, 413-416. doi: 10.1038/hdy.1976.106

Karssen, C. M., Brinkhorst-van der Swan, D. L. C., Breekland, A. E., and Koornneef, M. (1983). Induction of dormancy during seed development by endogenous abscisic acid: studies on abscisic acid deficient genotypes of Arabidopsis thaliana (L.) Heynh. Planta 157, 158-165. doi: 10.1007/BF0039 3650

Lijavetzky, D., Martínez, M. C., Carrari, F., and Hopp, E. H. (2000). QTL analysis and mapping of pre-harvest sprouting resistance in Sorghum. Euphytica 112, 125-135. doi: 10.1023/A:1003823829878

Liu, J., Osbourn, A., and Ma, P. (2015). MYB transcription factors as regulators of phenylpropanoid metabolism in plants. Mol. Plant 8, 689-708. doi: 10.1016/j. molp.2015.03.012

Lopez-Molina, L., Mongrand, S., McLachlin, D. T., Chait, B. T., and Chua, N. H. (2002). ABI5 acts downstream of ABI3 to execute an ABA-dependent growth arrest during germination. Plant J. 32, 317-328. doi: 10.1046/j.1365-313X.2002. 01430.x

McCarty, D. R., Carson, C. B., Stinard, P. S., and Robertson, D. S. (1989). Molecular analysis of Viviparous-1, an abscisic acid-insensitive mutant of maize. Plant Cell 1, 523-532. doi: 10.1105/tpc.1.5.523

Morris, G. P., Ramu, P., Deshpande, S. P., Hash, C. T., Shah, T., Upadhyaya, H. D., et al. (2013). Population genomic and genome-wide association studies of agroclimatic traits in sorghum. Proc. Natl. Acad. Sci. U.S.A. 110, 453-458. doi: $10.1073 /$ pnas. 1215985110

Nakamura, S., Abe, F., Kawahigashi, H., Nakazono, K., Tagiri, A., Matsumoto, T., et al. (2011). A wheat homolog of MOTHER OF FT AND TFL1 acts in the regulation of germination. Plant Cell 23, 3215-3229. doi: 10.1105/tpc.111. 088492

Ogawa, M., Hanada, A., Yamauchi, Y., Kuwahara, A., Kamiya, Y., and Yamaguchi, S. (2003). Gibberellin biosynthesis and response during Arabidopsis seed germination. Plant Cell 15, 1591-1604. doi: 10.1105/tpc.01 1650

Paterson, A. H., Bowers, J. E., Bruggmann, R., Dubchak, I., Grimwood, J., Gundlach, H., et al. (2009). The Sorghum bicolor genome and the diversification of grasses. Nature 457, 551-556. doi: 10.1038/nature07723

Pérez-Flores, L. J., Carrari, F., Osuna-Fernández, H. R., Enciso, S., Stanelloni, R., Sánchez, R. A., et al. (2003). Expression analysis of a GA 20-oxidase in embryos from two sorghum lines with contrasting dormancy: possible participation of this gene in the hormonal control of germination. J. Exp. Bot. 54, 2071-2079. doi: $10.1093 /$ jxb/erg233

Quinby, J. R., and Karper, R. E. (1961). Inheritance of duration of growth in the milo group of sorghum. Crop Sci. 1, 8-10. doi: 10.2135/cropsci1961. 0011183X000100010004x

Reeves, W. M., Lynch, T. J., Mobin, R., and Finkelstein, R. R. (2011). Direct targets of the transcription factors ABA-Insensitive ABI4 and ABI5 reveal synergistic action by ABI4 and several bZIP ABA response factors. Plant Mol. Biol. 75, 347-363. doi: 10.1007/s11103-011-9733-9

Rieu, W. I., Eriksson, S., Powers, S. J., Gong, F., Griffiths, J., Woolley, L., et al. (2008). Genetic analysis reveals that C19-GA 2-oxidation is a major gibberellin inactivation pathway in Arabidopsis. Plant Cell 20, 2420-2436. doi: 10.1105/tpc. 108.058818

Robichaud, C. S., Wong, J., and Sussex, I. M. (1980). Control of in vitro growth of viviparous embryo mutants of maize by abscisic acid. Dev. Genet. 1, 325-330. doi: 10.1002/dvg.1020010405

Rodríguez, M. V., Barrero, J., Corbineau, F., Gubler, F., and Benech-Arnold, R. (2015). Dormancy in cereals (not too much, not so little): About the mechanisms behind this trait. Seed Sci. Res. 25, 99-119. doi: 10.1017/S096025 8515000021

Rodríguez, M. V., Mendiondo, G. M., Cantoro, R., Auge, G. A., Luna, V., Masciarelli, O., et al. (2012). Expression of seed dormancy in grain sorghum lines with contrasting pre-harvest sprouting behavior involves differential regulation of gibberellin metabolism genes. Plant Cell Physiol. 53, 64-80. doi: $10.1093 /$ pcp/pcr154

Rodríguez, M. V., Mendiondo, G. M., Maskin, L., Gudesblat, G. E., Iusem, N. D., and Benech-Arnold, R. L. (2009). Expression of ABA signalling genes and ABI5 protein levels in imbibed Sorghum bicolor caryopses with contrasting dormancy and at different developmental stages. Ann. Bot. 104, 975-985. doi: 10.1093/aob/ mcp 184

Steinbach, H. S., Benech-Arnold, R. L., Kristof, G., Sanchez, R. A., and Marcucci Poltri, S. (1995). Physiological basis of pre-harvest sprouting resistance in Sorghum bicolor (L.) Moench. ABA levels and sensitivity in developing embryos of sprouting resistant and susceptible varieties. J. Exp. Bot. 45, 701-709. doi: 10.1093/jxb/46.6.701

Steinbach, H. S., Benech-Arnold, R. L., and Sánchez, R. A. (1997). Hormonal regulation of dormancy in developing Sorghum seeds. Plant Physiol. 113, 149-154. doi: 10.1104/pp.113.1.149

Stephens, J. C., Miller, F. R., and Rosenow, D. T. (1967). Conversion of alien sorghums to early combine genotypes. Crop Sci. 7:396. doi: 10.2135/ cropsci1967.0011183X000700040036x

Suzuki, M., Ketterling, M. G., Li, Q.-B., and Mc Carty, D. R. (2003). Viviparous1 alters global gene expression patterns through regulation of abscisic acid signaling. Plant Physiol. 132, 1664-1677. doi: 10.1104/pp.103.02 2475 
Waniska, A. R. D., and Rooney, W. (2002). "Structure and chemistry of the sorghum caryopsis," in Sorghum Origin, History, Technology, and Production, eds C. Wayne Smith and R. A. Frederiksen (Hoboken, NJ: Wiley Series in Crop Science), 45-53.

Wu, Y., Li, X., Xiang, W., Zhu, C., Lin, Z., Wu, Y., et al. (2012). Presence of tannins in sorghum grains is conditioned by different natural alleles of Tannin1. Proc. Natl. Acad. Sci. U.S.A. 109, 10281-10286. doi: 10.1073/pnas.1201700109

Yamaguchi, M., Fujimoto, H., Hirano, K., Araki-Nakamura, S., OhmaeShinohara, K., Fujii, A., et al. (2016). Sorghum Dw1, an agronomically important gene for lodging resistance, encodes a novel protein involved in cell proliferation. Sci. Rep. 6:28366. doi: 10.1038/srep28366
Conflict of Interest Statement: The authors declare that the research was conducted in the absence of any commercial or financial relationships that could be construed as a potential conflict of interest.

Copyright (c) 2018 Benech-Arnold and Rodríguez. This is an open-access article distributed under the terms of the Creative Commons Attribution License (CC BY). The use, distribution or reproduction in other forums is permitted, provided the original author(s) and the copyright owner are credited and that the original publication in this journal is cited, in accordance with accepted academic practice. No use, distribution or reproduction is permitted which does not comply with these terms. 